\title{
Maternal risk behavior and caries incidence in children with sickle cell disease
}

Felipe Fagundes SOARES

Maria Cristina Teixeira CANGUSSU

Maria Isabel Pereira VIANNA

Thais Regis Aranha ROSSI

Anderson Santos CARVALHO

Maria Goretti Silva BRITO

Universidade Federal da Bahia - UFBA, Faculdade de Odontologia, Departamento de Odontologia Social e Pediátrica, Salvador, BA, Brazil.

Declaration of Interests: The authors certify that they have no commercial or associative interest that represents a conflict of interest in connection with the manuscript.

Corresponding Author:

Felipe Fagundes Soares

E-mail: felipefagundes@outlook.com

DOI: 10.1590/1807-3107BOR-2016.vol30.0007

Submitted: Sep 29, 2014

Accepted for publication: Jul 16, 2015

Last revision: Aug 24, 2015

\begin{abstract}
The aim of this study was to analyze the incidence of caries, in relation to maternal risk behaviors and clinical conditions representing different levels of sickle cell disease severity. A total of 295 children aged 6 to 60 months participated in this cohort conducted from August 2007 to December 2008. They were diagnosed and monitored by the referral service of the state. Interviews were made with families to identify sociodemographic variables, and an oral exam was performed to determine dental caries. The SRQ (Self Report Questionnaire) scale was used to diagnose the presence of common mental disorders, and the CAGE (Cut down, Annoyed, Guilty and Eye opener) was applied to determine abusive use of alcohol. The absolute and relative frequencies of the variables of interest were analyzed by Chi-square and Mann-Whitney, with a 5\% significance level. The incidence variables were analyzed according to the logistic regression model, with a confidence interval of $95 \%$. Caries incidence $(1.98 ; \mathrm{SD}=4.68)$ was higher in the HbSS genotype. There was a statistically significant association between caries incidence and both abusive use of alcohol $(32.43 \%$, $\mathrm{RR}=1.99 ; 1.05-3.78 ; 95 \% \mathrm{CI})$ and common mental disorders $(8.77 \%$ $\mathrm{RR}=0.37 ; 0.15-0.93 ; 95 \% \mathrm{CI})$. There was also an association between caries incidence and maternal risk behavior, indicating that the care network should be expanded to include patients with sickle cell disease.
\end{abstract}

Keywords: Oral Health; Dental Caries; Anemia, Sickle Cell; Cohort Studies.

\section{Introduction}

Sickle cell anemia (SCA) is the most prevalent hemoglobinopathy in Brazil ${ }^{1}$. It is estimated that 3500 new cases are diagnosed each year. Bahia has the highest prevalence of sickle cell disease $(1: 650)^{1}$ of all the Brazilian states. SCA is hereditary, characterized by autosomal recessive genes, and is caused by a mutation on chromosome 11. This leads to a structural modification responsible for changes in the stability, solubility and structure of erythrocytes, which take on a sickle shape when exposed to low oxygen tension, acidosis or dehydration. . $3,4^{2}$

Pediatric patients usually have a history of multiple hospitalizations for pain crises, episodes of severe anemia, blood transfusions and recurrent periods of pulmonary infections. Children constitute the age group most vulnerable to severe symptoms, especially when diagnosed with the HbSS genotype. ${ }^{3}$ 
In the oral cavity, SCA can cause diastemata, delays in tooth eruption, ${ }^{5,6,7}$ malocclusion and glossitis. ${ }^{6,7,8,9}$ There are no studies in the literature containing conclusive data related to the prevalence of caries and periodontal disease in children afflicted by SCA, ${ }^{10,11}$ despite the existence of biological plausibility for an association between incidence of caries and severity of the disease.

It is reported that the quality of life and the children's family situation are critical in determining the process of health and disease. ${ }^{12}$ The greater incidence of dental caries in children is connected to a poorly structured family context, as well as worse health conditions in socially marginalized areas. ${ }^{13}$ These phenomena are also observed in regard to the impact that a chronic illness has on a family. ${ }^{14}$ A worse family context can be observed when the mother is an alcoholic or/and has a common mental disorder. ${ }^{12}$ Both conditions characterize maternal risk behaviors, ${ }^{12,13,14}$ and are associated with a higher caries experience in children. ${ }^{13,15}$

The aim of this study was to associate dental caries incidence to maternal risk behaviors and clinical conditions representing the levels of severity of this disease (presence of HbSS genotype, occurrence of pain crises, need for hospitalization and blood transfusions) by performing six-month follow-up studies on children aged 06-60 months, diagnosed and monitored by the state of Bahia's referral service from August 2007 to December 2008.

\section{Methodology}

A prospective cohort study was conducted. The population was established in August 2007 with children aged at least 6 months, who did not present with a history showing clinically severe conditions (hospitalization and blood transfusion) and were regularly monitored by the Serviço de Hematologia da Divisão de Triagem Neonatal of Associação dos Pais e Amigos dos Excepcionais - APAE (the Association of Parents and Friends of Exceptional Children) in Salvador-BA, the only service accredited by the Ministério da Saúde - MS and the Secretaria de Saúde da Bahia - SESAB as a referral center for the treatment, diagnosis and screening of neonates in the state.

The inclusion criteria comprised a minimum age of six months, diagnostic confirmation of sickle cell disease, at least two clinical consultations at the health service with an interval of at least 6 months - when interviews/caries examinations were conducted - and complete information regarding both the children's primary risk variables and the outcome variable. The exclusion criteria comprised inability to meet the above requirements and refusal to participate in the study. A total of 409 children, $41.9 \%$ of the initial sample, were excluded after missing appointments scheduled by the referral service. These cases made it difficult to perform a follow-up, and, consequently, presented a bias in the survey.

In all, 295 children were followed until December 2008, representing one year and 6 months for this cohort. Each child was assessed twice with an average interval of 8 months. The exams and the interview took place during the child's regular visit to the health service.

After signing the terms of informed consent, parents or guardians were asked questions related to socioeconomic status (skin color, family income, level of maternal education, age of mother and child, marital status), sickle-cell-related clinical conditions (morbidity in the last six months, pain crises, hospitalization and blood transfusion, as well as the genotype of the disease); and maternal risk behavior (common mental health disorders, alcohol abuse).

The genotype was informed by the child's guardian and confirmed by the medical records. "Common mental health disorder" was diagnosed if eight or more questions on the Self Report Questionnaire - SRQ-20 $0^{16}$ received a positive response. In respect to the variable of "alcohol abuse," a positive response to two or more questions on the CAGE scale ${ }^{17}$ indicated its consideration. These questionnaires were validated in previous studies carried out in Brazil. 18,19

While awaiting their appointment with the hematologist, the children participated in oral health education activities (supervised brushing and guidance on oral hygiene) and were examined for dental caries according to the criteria established by the Oral Health Brazil ${ }^{20}$ survey.

A change in the child's health status was considered an incidental event. In relation to dental caries, this meant the development of another manifestation of the disease; in relation to the clinical conditions assessed 
and the variables related to maternal behavior, it meant any new events.

The data were collected by three trained and previously calibrated teams. Verification of inter-examiner and intra-examiner conformity identified a general agreement of $98 \%$ for caries and a kappa of 0.79 .

The absolute and relative frequencies of the variables of interest were analyzed using the Chi-square test. The Mann-Whitney tests measured the probability of a statistically significant difference between the median $\mathrm{dmft}$ - the number of decayed, missing and filled teeth - at baseline and at follow-up, as well as the probability of association between the median incidence of caries and the genotype. In this case, individuals who did not have the HbSS and HbSC genotypes were excluded. A significance level of $5 \%$ was used in these tests.

The association measure used was relative risk (RR) with a confidence interval of $95 \%$. The main outcome was dichotomized (individuals with new caries $=1$; individuals without new caries $=0$ ). The variables that were associated with the outcome in the univariate model, and that showed a p-value less than or equal to 0.05 , were analyzed using the multiple Poisson regression model.

The data was tabulated using Epi Info $6.04^{\circledR}$ (CDC, Atlanta, USA), and the statistical analysis was performed using Stata ${ }^{\circledR}$, version 12.0 (StataCorp LP, College Station, USA).

The research protocol for the study was submitted to and approved by the Research Ethics Committee of the Maternidade Climério de Oliveira (Universidade Federal da Bahia - UFBa), under number 014/2007. There are no conflicts of interest with the institution where the research was conducted (APAE/Salvador).

\section{Results}

A total of 295 children were followed. Their ages ranged from 6 to 60 months, with a mean age of 32.92 months ( $\mathrm{SD}=17.31$ ). Of this total, 145 were males (49.15\%) and 150 were females (50.85\%). Most were classified as brown (54.80\%), residing in the countryside $(76.62 \%)$, and with a family income below the minimum wage (74.40\%). As for genotype, 33.78\% were $\mathrm{HbSS}, 51.35 \%$ were $\mathrm{HbSC}$ and $14.87 \%$ belonged to other genotypes of less clinical relevance, and, for this reason, were not detailed in this investigation.

In respect to the children's family setting, the mother's average age was 26 years; $54.36 \%$ of the mothers had completed elementary and middle school, and $76.41 \%$ were married or had a common-law union with a partner. During the study period, $19.32 \%$ of new cases of common mental disorders and $12.54 \%$ of new cases of maternal alcohol abuse were identified in this group.

The variables for the clinical manifestations of the disease, i.e., presence of pain crises, need for hospitalization and blood transfusion, showed an incidence of $22.03 \%, 14.92 \%$ and $8.47 \%$, respectively. The degree of clinical vulnerability of the studied population becomes more evident when observing that a respective $70.85 \%$ (pain crisis), $55.17 \%$ (hospitalization) and 28.73\% (blood transfusion) of the patients had a history of these events occurring at least once from the baseline through the entire study period, according to the morbidity.

Description of $\mathrm{dmft}$ according to sickle cell condition showed that the HbSS group had a greater incidence of caries than the HbSC group (Table 1). There was no statistically significant association between the incidence of caries and the genotype $(p$-value $=0.34)$. On the other hand, there was a statistically significant difference between the baseline median dmft values $(0.00,0.00-0.00)$ and the follow-up values $(0.00,0.00-2.00)(\mathrm{p}$-value $=0.00)$, revealing an increase in caries not associated with the genotype of the disease over time.

Among the variables that represent clinical severity, the occurrence of a pain crisis as a risk factor was associated to the higher incidence of caries only in the crude analysis ( $R R=1.89,95 \% C I 1.01-3.58)$. In relation to maternal behavior variables, maternal alcohol abuse $(\mathrm{RR}=1.90,95 \% \mathrm{CI} 1.11-3.25)$ and common mental disorders $(\mathrm{RR}=0.40,95 \% \mathrm{CI}$ 0.17-0.98) were associated to outcome. These results were confirmed in the adjusted model (Table 2).

\section{Discussion}

This study examined the caries incidence, clinical conditions and maternal risk behavior of 295 children between 6 and 60 months of age, with sickle cell 
Table 1. Measures of central tendency and dispersion dmft second most significant genotypes of sickle cell disease in children 6-60 months in Bahia.

\begin{tabular}{|c|c|c|c|c|}
\hline \multirow{2}{*}{$\begin{array}{l}\text { Sickle cell disease } \\
\text { condition }^{+}\end{array}$} & \multicolumn{4}{|c|}{ Group Baseline* (first exam) } \\
\hline & $\mathrm{n}$ & $\mathrm{dmft}^{\dagger}$ & SD & Median(Q1-Q3) \\
\hline $\mathrm{HbSS}$ & 116 & 0.90 & 2.14 & $0.00(0.00-0.00)$ \\
\hline \multirow[t]{3}{*}{$\mathrm{HbSC}$} & 138 & 0.65 & 1.74 & $0.00(0.00-0.00)$ \\
\hline & \multicolumn{4}{|c|}{$\begin{array}{l}\text { Group Follow-up* } \\
\text { (second exam) }\end{array}$} \\
\hline & $\mathrm{n}$ & $\mathrm{dmft}^{\dagger}$ & SD & Median (Q1-Q3) \\
\hline $\mathrm{HbSS}$ & 116 & 2.69 & 5.23 & $0.00(0.00-2.75)$ \\
\hline \multirow[t]{3}{*}{$\mathrm{HbSC}$} & 138 & 1.87 & 4.75 & $0.00(0.00-0.25)$ \\
\hline & \multicolumn{4}{|c|}{ Caries incidence** } \\
\hline & $\mathrm{n}$ & $\mathrm{dmft}^{\dagger}$ & SD & Median (Q1-Q3) \\
\hline $\mathrm{HbSS}$ & 116 & 1.98 & 4.68 & $0.00(0.00-0.75)$ \\
\hline $\mathrm{HbSC}$ & 138 & 1.65 & 4.51 & $0.00(0.00-0.00)$ \\
\hline
\end{tabular}

${ }^{\dagger} \mathrm{dmft}$ - mean of decayed, missing and filled teeth

+41 individuals, both at baseline, as the follow-up represent other genotypes of sickle cell disease not evaluated in this association.

${ }^{*} p$-value $=0.00$ (Mann-Whitney's test) Comparing the occurrence of caries in the baseline group and follow-up group, it was found that there is a statistically significant difference.

${ }^{* *}$ p-value $=0.34$ (Kruskal-Wallis' test) There was no statistically significant association between caries incidence and genotype.

Table 2. Analysis of crude and adjusted risk relative (RR) between caries incidence and severity of clinical variables and maternal risk behavior in children aged 6 to 60 months with sickle cell disease in Bahia ( $n=295)$.

\begin{tabular}{|c|c|c|c|c|}
\hline & \multicolumn{2}{|c|}{ Caries incidence } & \multirow{2}{*}{$\begin{array}{c}\text { RR }(95 \% \mathrm{Cl}) \\
\text { Crude }\end{array}$} & \multirow{2}{*}{$\begin{array}{l}\text { RR (95\%Cl) } \\
\text { Adjusted** }\end{array}$} \\
\hline & $\mathrm{n}$ & $\%$ & & \\
\hline \multicolumn{5}{|c|}{ Pain crisis } \\
\hline Yes & 46 & 22.01 & $1.89(1.01-3.58)$ & $1.88(0.95-3.73)$ \\
\hline No & 10 & 11.63 & 1.00 & 1.00 \\
\hline \multicolumn{5}{|c|}{ Hospitalizations } \\
\hline Yes & 10 & 22.73 & $1.24(0.68-2.27)$ & - \\
\hline No & 46 & 18.33 & 1.00 & \\
\hline \multicolumn{5}{|c|}{ Transfusions } \\
\hline Yes & 4 & 16.00 & $0.83(0.33-2.11)$ & - \\
\hline No & 52 & 19.26 & 1.00 & \\
\hline \multicolumn{5}{|c|}{ Abusive use of alcohol } \\
\hline Yes & 12 & 32.43 & $1.90(1.11-3.25)$ & $1.99(1.05-3.78)$ \\
\hline No & 44 & 17.05 & 1.00 & 1.00 \\
\hline \multicolumn{5}{|c|}{ Common mental disorder } \\
\hline Yes & 5 & 8.77 & $0.40(0.17-0.98)$ & $0.37(0.15-0.93)$ \\
\hline No & 51 & 21.43 & 1.00 & 1.00 \\
\hline
\end{tabular}

**RR obtained by multivariate poisson regression analysis. disease, who were followed in a six-month cohort. No cohort studies were found in the literature which examined the clinical conditions and the family context; moreover, none related the impact of these conditions to the oral health of this group.

It is difficult to compare the results regarding oral health, because there are no other caries incidence studies in patients with sickle cell disease. Only two articles were found in the literature that investigated dental caries in children with sickle cell disease, both of which are cross-sectional studies. One described the clinical and oral health conditions, the socioeconomic status and the family context of 704 children in the state of Bahia, Brazil,$^{10}$ and the other associated caries prevalence to socioeconomic status in 160 children in Recife, Brazil. ${ }^{11}$ The dmft in these studies was $0.94(\mathrm{DP}= \pm 2.28)$ and 2.12, respectively. In the National Oral Health Survey (SB Brazil) of $2003,{ }^{20}$ the mean dmft for healthy Brazilian children aged 18-36 months was $1.07(\mathrm{SD}=2.40)$ and $1.00(\mathrm{SD}=2.24)$ in the northeast region. As for the 5 year-old age group, the $\mathrm{dmft}$ recorded in the SB Brazil $2010^{21}$ was 2.43 (95\%CI 2.22-2.63) for the country and 1.70 (95\%CI 1.36-2.04) for the city of Salvador, the Bahia state capital where the research was conducted. In the present study, the dmft of the follow-up group $(2.69, \mathrm{SD}=5.23)$ was higher than that of Brazil and that of Bahia.

According to the literature, ${ }^{22,23}$ sickle cell disease does not predispose individuals to caries, at least not directly. In the two articles found in the literature referred to above, there was no statistically significant association between caries incidence and genotype. HbSS showed a higher caries incidence, as was observed in other studies with adults ${ }^{22,23}$ and adolescents, ${ }^{24}$ as compared with the HbSC genotype and control groups. Ralstrom ${ }^{24}$ attributed this association to the lower severity of clinical manifestations of the HbSC versus the HbSS genotype.

Despite the lack of association between the incidence of caries and the genotype for more severe disease, it was found that the morbidity for pain crises was a risk factor for caries incidence. Pain crisis is the most common clinical event and the primary reason for seeking medical services and hospitalization; ${ }^{25}$ for this reason, the children 
reporting this symptom in this study were considered as having a greater degree of severity than those who never presented it. Pain crisis was the event that most contributed to a greater burden of disease on Cameroonian parents. ${ }^{26}$

In respect to this severe clinical profile, Guimarães and collaborators, ${ }_{1}^{14}$ in their study on the daily lives of families of children and adolescents with sickle cell disease, reported that mothers tend to be overprotective and burdened when they need to spend time caring for their children and have to give up social functions. An impact on the family environment was also reported in this study, namely the inability to accept the disease and the fear of death, to the extent that the family experienced periods of greater or lesser control of the disease and could not handle the situation, feeling lost and hopeless.

According to Martin and Angelo, ${ }^{27}$ the mother is largely responsible for family health in low-income communities, since she represents the center of the family. It is the mother who plays the leading role in controlling important variables which determine caries, such as eating habits and oral hygiene. ${ }^{13}$ Accordingly, the variables related to maternal behavior - the presence of common mental disorders and alcohol abuse - are important factors in constructing the family context. In this study, maternal risk behavior variables were associated with caries incidence. This goes to show how family background affects the oral health of these children.

Sousa et al. ${ }^{13}$ also found an association between family dysfunction, resulting from common maternal mental disorder symptoms and alcoholism, and the incidence of caries in children aged 2-3 years with a $\mathrm{dmft}$ of $0.72(\mathrm{SD}=1.8)$.

It has been suggested that sickle cell disease, its social representations and its clinical symptoms, which tend to worsen with age, are factors that trigger and/or contribute to building a negative family environment, and, consequently, to a worsening in oral health.
Despite the relevance of sickle cell disease to the general and oral health of stricken children, the limitations of this study are worth noting, including the convenience of the sample, which consisted of those requiring health services and already receiving medical and dental care. As a result, it is important to note that the sample does not allow inference of these results to all patients with sickle cell disease, only to the sample population.

Another consideration is that that sample size represented not only a limitation, but also a difficulty, since case follow-up was dependent on the patients' return for a follow-up appointment with the hematologist. Thus, the sample may not have been enough for some variables to become more expressive. Furthermore, the strategy of bivariate analysis for caries incidence was adopted because caries was the most important oral manifestation, but further studies should not discard the existence of other associations.

\section{Conclusions}

In this sample, an association between the incidence of caries and maternal behavior (alcohol abuse, maternal depression) was verified. The results also give indications of the association between sickle cell disease severity and a higher caries incidence, a finding that should be followed up in subsequent studies to confirm this relationship.

The significant loss of patients between the baseline and the follow-up suggests that there may be significant barriers in accessing the state's referral center. Studies on the access to these services still lack in the literature, indicating that further evaluation is required.

\section{Acknowledgments}

We would like to thank Associação dos Pais e Amigos dos Excepcionais - APAE/Salvador for their support and collaboration. This study was funded by the Fundação de Amparo à Pesquisa do Estado da Bahia - FAPESB. 


\section{References}

1. Cançado RD, Jesus JA. [Sickle cell disease in Brazil]. Rev Bras Hematol Hemoter. 2007;29(3):203-6. Portuguese. doi:10.1590/S1516-84842007000300002

2. De Franceschi L, Corrocher R. Established and experimental treatments for sickle cell disease. Haematologica. 2004;89(3):348-56.

3. Fonseca MA, Oueis HS, Casamassimo PS. Sickle cell anemia: a review for the pediatric dentistry. Pediatr Dent. 2007;29(2):159-69.

4. Switzer JA, Hess DC, Nichols FT, Adams RJ. Pathophysiology and treatment of stroke in sickle cell disease: present and future. Lancet Neural. 2006; 5(6):501-12.

5. Ramakrishna Y. Dental considerations in the management of children suffering from sickle cell disease: a case report. J Indian Soc Pedod Prev Dent. 2007;25(3):140-3. doi:0.4103/0970-4388.36566

6. Alves PV, Alves DK, Souza MM, Torres SR. Orthodontic treatment of patients with sickle cell anemia. Angle Orthod. 2006;76(2):269-73.

7. Oredugba FA. Hypodontia in an adolescent with the HbSC genotype: a case report. Inter J Ped Dent. 2005;15(6):455-58. doi:0.1111/j.1365-263X.2005.00648.x

8. Rosa LJ, Magalhães MH. Aspectos gerais e bucais da anemia falciforme e suas implicações no atendimento odontológico. Rev Assoc Paul Cir Dent. 2002;56(5):377-81.

9. Kavadia-Tsatala S, Kolokytha O, Kaklamanos EG, Antoniades K, Chasapopoulou E. Mandibular lesions of vasoocclusive origin in sickle cell hemoglobinopathy. Odontology. 2004;92(1):68-72. doi:0.1007/s10266-004-0036-3

10. Soares FF, Rossi TR, Brito MG, Vianna MI, Cangussu MC. Condições de saúde bucal e fatores sociodemográficos de crianças de 6 a 96 meses com doença falciforme no Estado da Bahia. Rev Odontol UNESP. 2010;39(2):115-21.

11. Luna AC, Rodrigues MJ, Menezes VA, Marques KM, Santos FA. Caries prevalence and socioeconomic factors in children with sickle cell anemia. Braz Oral Res. 2012;26(1):43-49. doi:0.1590/S1806-83242012000100008

12. .Martins MF, Costa JS, Saforcada ST, Cunha MD. [Quality of the environment and associated factors: a pediatric study in Pelotas, Rio Grande do Sul, Brazil]. Cad Saude Publica. 2004;20(3):710-8. Portuguese. doi:10.1590/S0102-311X2004000300007

13. Souza MA, Vianna MI, Cangussu MC. [Family dysfunction related to maternal depression and/or alcoholism in the family and dental caries in children from two to three years old]. Rev Bras Saude Matern Infant. 2006;6(3):309-17. Portuguese. doi:10.1590/S1519-38292006000300007

14. Guimarães TM, Miranda WL, Tavares MM. [The day-to-day life of families with children and adolescents with sickle cell anemia]. Rev Bras Hematol Hemoter. 2009;31(1):9-14. Portuguese. doi:10.1590/S1516-84842009005000002

15. Almeida TF, Vianna MI, Cabral MB, Cangussu MC, Floriano FR. Family context and incidence of dental caries in preschool children living in areas covered by the Family Health Strategy in Salvador, Bahia State, Brazil. Cad Saude Publica. 2012;28(6):1183-95. doi:10.1590/S0102-311X2012000600017

16. World Health Organization, Division of Mental Health. A user's guide to the selfreporting questionnaire (SRQ). Geneva: World Health Organization; 1994.

17. Ewing JA. Detecting alcoholism: the CAGE questionnaire. JAMA. 1984;252(14):1905-7. 1 doi:0.1001/jama.1984.03350140051025.

18. Mari JJ, Williams P. A validity study of a psychiatric screening questionnaire (SRQ-20) in primary care in the city of São Paulo. Br J Psychiatry 1986;148(1):23-6. doi:0.1192/bjp.148.1.23

19. Masur J, Monteiro MJ. Validation of the "CAGE" alcoholism screening test in a Brazilian psychiatric inpatient hospital setting. Braz J Med Biol Res. 1983;16(3):215-8.

20. Ministério da Saúde (BR), Secretaria de Atenção à Saúde, Departamento de Atenção Básica. Projeto SB Brasil 2003: condições de saúde bucal da população brasileira 2002-2003: resultados principais. Brasília, DF: Ministério da Saúde, 2004.

21. Ministério da Saúde (BR), Secretaria de Atenção à Saúde, Departamento de Atenção Básica. Projeto SB Brasil 2010: condições de saúde bucal da população brasileira 2009-2010: resultados principais. Brasília (DF): Ministério da Saúde; 2011.

22. Passos CP, Santos PR, Aguiar MC, Cangussu MC, Toralles $\mathrm{MB}$, da Silva MC et al. Sickle cell disease does not predispose to caries or periodontal disease. Spec Care Dentist. 2012;32(2):55-60. doi:0.1111/j.1754-4505.2012.00235.x

23. Laurence B, George D, Woods D, Shosanya A, Katz RV, Lanzkron $S$ et al. The association between sickle cell disease and dental caries in African Americans. Spec Care Dentist, 2006;26(3):95-100. doi:0.1111/j.1754-4505.2006.tb01430.x

24. Ralstrom EF. The impact of sickle cell disease on oral health-related quality of life. Pediatr Dent. 2014;36(1):24-8.

25. Loureiro MM, Rozenfeld S, Portugal RD. Acute clinical events in patients with sickle cell disease: epidemiology and treatment. Rev Bras Hematol Hemoter. 2008;30(2):95-100. doi:10.1590/S1516-84842008000200005

26. Wonkam A, Zameyo C, Mbanya D, Ngogang J, Ramesar R, Andwafo FF. Psychosocial burden of sickle cell disease on parents with an affected child in Cameroon. J Genet Couns 2014;23(2):192-201. doi:0.1007/s10897-013-9630-2

27. Martin VB, Angelo M. [The meaning of the health concept through the perspective of families under personal and social risk situations]. Rev Latino-am enfermagem. 1998;6(5):45-51. Portuguese. doi:10.1590/S0104-11691998000500006 